\title{
Prediction of the survival and functional ability of severe stroke patients after ICU therapeutic intervention Moussa Riachy*1, Frida Sfeir ${ }^{1}$, Ghassan Sleilaty ${ }^{2}$, Samer Hage-Chahine ${ }^{\dagger 3}$, Georges Dabar ${ }^{1}$, Taha Bazerbachi ${ }^{1}$, Zeina Aoun-Bacha ${ }^{1}$, Georges Khayat $^{1}$ and Salam Koussa ${ }^{\dagger 3}$
}

Address: ${ }^{1}$ Department of Pulmonary and Critical Care Medicine, Hotel Dieu de France, Beirut, Lebanon, ${ }^{2}$ Department of Cardiothoracic Surgery, Hotel Dieu de France, Beirut, Lebanon and ${ }^{3}$ Department of Neurology, Hotel Dieu de France, Beirut, Lebanon

Email: Moussa Riachy* - riachy@dm.net.lb; Frida Sfeir - fridasfeir@hotmail.com; Ghassan Sleilaty - sanasl@inco.com.lb; Samer HageChahine - samerhagechahine@hotmail.com; Georges Dabar - gdabar@cyberia.net.lb; Taha Bazerbachi - tbazarbachi@hotmail.com; Zeina Aoun-Bacha - zeinaabacha@yahoo.com; Georges Khayat - gck@data2.dm.net.lb; Salam Koussa - koussalam@hotmail.com

* Corresponding author †Equal contributors

Published: 26 June 2008

BMC Neurology 2008, 8:24 doi:10.1 | 86/| 47| |-2377-8-24
Received: 16 December 2007

Accepted: 26 June 2008

This article is available from: http://www.biomedcentral.com/I47I-2377/8/24

(c) 2008 Riachy et al; licensee BioMed Central Ltd.

This is an Open Access article distributed under the terms of the Creative Commons Attribution License (http://creativecommons.org/licenses/by/2.0), which permits unrestricted use, distribution, and reproduction in any medium, provided the original work is properly cited.

\begin{abstract}
Background: This study evaluated the benefits and impact of ICU therapeutic interventions on the survival and functional ability of severe cerebrovascular accident (CVA) patients.

Methods: Sixty-two ICU patients suffering from severe ischemic/haemorrhagic stroke were evaluated for CVA severity using APACHE II and the Glasgow coma scale (GCS). Survival was determined using Kaplan-Meier survival tables and survival prediction factors were determined by Cox multivariate analysis. Functional ability was assessed using the stroke impact scale (SIS-16) and Karnofsky score. Risk factors, life support techniques and neurosurgical interventions were recorded. One year post-CVA dependency was investigated using multivariate analysis based on linear regression.
\end{abstract}

Results: The study cohort constituted $6 \%$ of all CVA (37.8\% haemorrhagic/62.2\% ischemic) admissions. Patient mean(SD) age was 65.8(I2.3) years with a I:I male: female ratio. During the study period 16 patients had died within the ICU and seven in the year following hospital release.

The mean(SD) APACHE II score at hospital admission was I4.9(6.0) and ICU mean duration of stay was II.2(I5.4) days. Mechanical ventilation was required in $37.1 \%$ of cases. Risk ratios were; GCS at admission 0.8(0.14), $(p=0.024)$, APACHE II I.II $(0.1 I),(p=0.05)$ and duration of mechanical ventilation I.07(0.07), $(p=0.046)$. Linear coefficients were: type of CVA - haemorrhagic versus ischemic: $-18.95(4.58)(p=0.007), G C S$ at hospital admission: $-6.83(I .08),(p=0.001)$, and duration of hospital stay $-0.38(0.14),(p=0.40)$.

Conclusion: To ensure a better prognosis CVA patients require ICU therapeutic interventions. However, as we have shown, where tests can determine the worst affected patients with a poor vital and functional outcome should treatment be withheld? 


\section{Background}

Cerebrovascular accidents (CVA) are currently the second most common cause of mortality in the world, and remain the most common cause of long-term disability in adults [1-4]. New therapeutic methods are being advanced to limit ischemic neuronal damage, although their benefits are debatable [5-8]. The setting up of intensive care units (ICU) for the treatment of acute CVAs has caused controversy for many years [9-15], although new evidence has established an increased patient survival rate and quality of life in ICU treated patients compared to those treated in medical departments [3,4,9-14]. CVA patient admission into ICUs has now become routine, but can not ensure better survival or provide less physical or mental dependence for every patient. After suffering a catastrophic neurological event the benefits of intensive care remain controversial, and may only serve to prolong the period before the patient's inevitable death [16].

The study aim was to predict the benefit and impact of various ICU therapeutic interventions on the survival and functional abilities of CVA patients who had suffered severe ischemic or haemorrhagic stroke.

\section{Methods}

This study was conducted at the Hôtel-Dieu de France university hospital in Beirut (Lebanon), linked to SaintJoseph University, which has 8 intensive care beds for emergency and medical services.

A study was made of 62 ICU patients suffering from severe ischemic or haemorrhagic CVA entering the ICU (via the emergency or neurology departments, or other hospital departments) over a retrospective period of 30 months (July 2000 to January 2003) and 12 months prospectively (January 2003 to January 2004). Exclusion criteria included patients who had suffered from sub-arachnoidal haemorrhage, extra-dural haematoma or transient ischemic attack.

CVA severity was measured using an acute physiology, age and chronic health evaluation (APACHE II: range 0 to 71) [17] and a Glasgow coma scale (GCS: range 3 to 15) neurological assessment $[18,19]$ at admission, 48 hours after admission and at ICU discharge. Patient survival was determined using Kaplan-Meier survival tables. The patients' state of dependence and functional abilities were measured using stroke impact scale-16 (SIS-16) [20,21], which provides a measurement of a patient's capacity to perform daily activities. Additionally, their general health status was assessed using a Karnofsky Score (range 0 to 100) $[22,23]$ before ICU admission, at hospital discharge, and at 3 months and 1 year post-CVA.
Continuous variables were expressed as means with their standard deviation (SD), whereas categorical variables were expressed as actual numbers and percentages. For quantitative variables, a student $t$-test was used to compare the means of two categories. For more than two categories, an analysis of variance was used, and if there were statistically significant differences a post-hoc test was performed. Categorical variables were analyzed using a Chisquare test. A repeated-measures ANOVA was made to study the evolution of quantitative variables over time, and a Spearman correlation was used to study the relationship between neurological and general health severity scores.

Determination of independent variables predicting a CVA patient's physical dependency at discharge and after one year was made using a univariate analysis, supplemented by a multivariate linear regression.

Survival analysis tables were used to assess CVA patient survival. Univariate qualitative variables were compared using the log rank method. A multivariate analysis of survival predictive factors was made using the Cox proportional hazards technique. All predictive factors with a univariate $\mathrm{p}<0.1$ were entered in the multivariate model. To adjust for testing multiple hypotheses we performed the Holm stepdown Sidak procedure for multiple comparisons ( $\left.\mathrm{P}^{\prime} \mathrm{sds}\right)$. All other tests were considered statistically significant for a $\mathrm{p}$-value $<0.05$.

The statistical software used in this study was SPSS v13 (SPSS Inc, Chicago, Illinois).

\section{Results}

Of the 62 patients studied, $47(75.8 \%)$ came from the emergency department, 5 (8.1\%) from the neurology department, $5(8.1 \%)$ came from other medical departments within the hospital and $5(8.1 \%)$ were transferred from another hospital. The male: female ratio was $1: 1$ with a mean (SD) age of 65.8 (12.3) years.

Thirty three patients (53.2\%) suffered from embolic CVA, 17 (27.4\%) from haemorrhagic CVA and 12 (19.4\%) from thrombotic CVA. Half the CVA cases were in the carotid artery territory, 33.9\% were in the vertebro-basilar artery territory and the remaining cases were in the cortical and subcortical areas. Risk factors (infection and cardiac problems) were identical for both ischemic and haemorrhagic stroke, except for atrial fibrillation which was found in 12 patients with ischemic stroke $(\mathrm{p}<0.001)$.

At admission the mean APACHE II values, Karnofsky score and the SIS-16/80 were 14.90 (6.0), 91.50 and 74.93 respectively, which indicated a good initial functional state. The majority of patients were completely 
independent with an average Karnofsky score higher than 90 for both ischemic and haemorrhagic CVA. The GCS/15 at admission had a mean of 9.9.

A univariate comparison between survivors and non-survivors with respect of all risk factors studied was made and is presented in Table 1. Continuous normal data are represented as mean(SD), continuous non-normal data and ordinal data are represented as median (1st-3rd quartile) and categorical data are represented as frequencies.

The ICU interventions and their significance in treating ischemic and haemorrhagic CVA are presented in Table 2.
Additionally, it was found that; 10 (16.1\%) patients in the ischemic group received thrombolysis, 34 (54.8\%) had received a naso-gastric tube to avoid difficulties in swallowing, 23 (37\%) underwent mechanical ventilation and five patients (8.1\%) underwent surgical intervention.

A receiver operating characteristic curves (ROC) was plotted for APACHE II and GCS; the area under the ROC curve was $0.834(95 \%$ CI: 0.722 to 0.946$)\left(\mathrm{p}<10^{-3}\right)$ for APACHE II and 0.828 (95\% CI: 0.715 to 0.940$)\left(\mathrm{p}<10^{-3}\right)$ for GCS. When the APACHE II and GCS curves are compared, the area under the ROC curve of APACHE II showed no significant differences in p-values. (Fig. 1).

Table I: Univariate comparison between survivors and non-survivors with respect of all risk factors studied

\begin{tabular}{|c|c|c|c|c|}
\hline & Survivors $(n=46)$ & Non survivors $(n=16)$ & p-value & $P^{\prime}$ sds \\
\hline Age (years) & $63.9 \pm 11.7$ & $71.1 \pm 13.0$ & 0.043 & 0.681 \\
\hline Female gender & $50.0 \%$ & $50.0 \%$ & 0.999 & 1.000 \\
\hline Hypertension & $71.7 \%$ & $56.3 \%$ & 0.254 & 0.995 \\
\hline Diabetes mellitus & $23.9 \%$ & $37.5 \%$ & 0.294 & 0.996 \\
\hline Dyslipidemia & $28.3 \%$ & $12.5 \%$ & 0.205 & 0.990 \\
\hline COPD & $2.2 \%$ & $0.0 \%$ & 0.999 & 1.000 \\
\hline Myocardial infarction & $10.9 \%$ & $18.8 \%$ & 0.418 & 0.999 \\
\hline CABG & $4.3 \%$ & $6.3 \%$ & 0.999 & 1.000 \\
\hline Cardiac failure & $6.5 \%$ & $25.0 \%$ & 0.044 & 0.675 \\
\hline Atrial fibrillation & $17.4 \%$ & $25.0 \%$ & 0.507 & 0.999 \\
\hline Renal failure & $19.6 \%$ & $12.5 \%$ & 0.524 & 0.999 \\
\hline Cancer & $2.2 \%$ & $6.3 \%$ & 0.453 & 0.999 \\
\hline Smoking & $30.4 \%$ & $12.5 \%$ & 0.158 & 0.977 \\
\hline Hemorrhagic stroke & $26.1 \%$ & $31.3 \%$ & 0.690 & 0.999 \\
\hline Previous stroke & $26.1 \%$ & $25 \%$ & 0.932 & 1,000 \\
\hline Thrombolysis & $21.7 \%$ & $0 \%$ & 0.042 & 0.712 \\
\hline Karnofsky score on admission & $100(100-100)$ & $80(80-100)$ & 0.029 & 0.621 \\
\hline SIS I6/80 score on admission & $80(80-80)$ & $80(70-80)$ & 0.290 & 0.997 \\
\hline Apache score on admission & $13(10-16)$ & $20(18-23)$ & $<0.001$ & 0.037 \\
\hline GCS score on admission & $11(9-13)$ & $6(4-10)$ & $<0.001$ & 0.036 \\
\hline Apache score after 48 hours & $12(8-18)$ & $19(17-24)$ & 0.003 & 0.097 \\
\hline GCS score after 48 hours & $12(9-14)$ & $8(4-11)$ & 0.001 & 0.035 \\
\hline Sedative treatment & $4.3 \%$ & $25.0 \%$ & 0.034 & 0.669 \\
\hline Anti-hypertensive treatment & $65.2 \%$ & $75.0 \%$ & 0.471 & 0.999 \\
\hline Anti-coagulant treatment & $78.3 \%$ & $62.5 \%$ & 0.215 & 0.990 \\
\hline Anti-epileptic drugs & $15.2 \%$ & $37.5 \%$ & 0.059 & 0.768 \\
\hline Diuretics & $17.4 \%$ & $438 \%$ & 0.034 & 0.658 \\
\hline Corticosteroids & $13.0 \%$ & $0.0 \%$ & 0.325 & 0.997 \\
\hline Gastric tube & $43.5 \%$ & $87.5 \%$ & 0.002 & 0.068 \\
\hline Surgery & $4.3 \%$ & $18.8 \%$ & 0.103 & 0.918 \\
\hline Infection & $43.5 \%$ & $62.5 \%$ & 0.190 & 0.988 \\
\hline Cardiac complications & $19.6 \%$ & $25.0 \%$ & 0.646 & 0.999 \\
\hline Tracheostomy & $10.9 \%$ & $6.3 \%$ & 0.999 & 0.999 \\
\hline Respiratory physiotherapy & $15.2 \%$ & $6.3 \%$ & 0.357 & 0.998 \\
\hline Mechanical ventilation duration & $9(8-13)$ & $5(2-16)$ & 0.554 & 0.998 \\
\hline ICU length of stay & $4(2-12)$ & $9(4-2 I)$ & 0.042 & 0.699 \\
\hline Apache score on ICU discharge & $10(5-14)$ & $16(15-20)$ & 0.040 & 0.706 \\
\hline GCS score on ICU discharge & $13(11-15)$ & $11(8-11)$ & 0.042 & 0.686 \\
\hline
\end{tabular}

COPD: Chronic obstructive pulmonary disease; CABG: Coronary artery bypass grafting. GCS: Glasgow coma scale. ICU: Intensive care unit. Continuous normal data are represented as mean \pm standard deviation. Continuous non normal data and ordinal data are represented as median (I st quartile - $3^{\text {rd }}$ Quartile); Categorical data are represented as frequencies (Percentage). P'sds is the adjusted P value derived from the Holm-Sidak step-down procedure to correct for multiple comparisons. 
Table 2: The number and percentage of ICU interventions for ischemic and haemorrhagic CVA and their significance (p-value)

\begin{tabular}{|c|c|c|c|c|c|c|}
\hline \multirow[t]{2}{*}{ Intervention } & \multicolumn{2}{|c|}{ Ischemic } & \multicolumn{2}{|c|}{ Haemorrhagic } & \multirow[t]{2}{*}{ p-value } & \multirow[t]{2}{*}{ P' sds } \\
\hline & $\mathrm{N}$ & $\%$ & $\mathrm{~N}$ & $\%$ & & \\
\hline Sedation & 2 & 4.45 & 4 & 23.53 & 0.043 & 0.296 \\
\hline Anti-hypertensives & 28 & 62.22 & 14 & 82.35 & 0.223 & 0.717 \\
\hline Anti-coagulants & 42 & 93.33 & 4 & 23.53 & 0.001 & 0.011 \\
\hline Anti-epileptics & 4 & 8.89 & 9 & 52.94 & 0.001 & 0.010 \\
\hline Osmotic diuretics & 8 & 17.78 & 7 & 41.18 & 0.094 & 0.499 \\
\hline Steroids & 4 & 8.89 & 2 & 11.76 & 0.662 & 0.987 \\
\hline Nasogastric tube & 22 & 48.89 & 12 & 70.59 & 0.159 & 0.646 \\
\hline Surgery & 1 & 2.22 & 4 & 23.52 & 0.018 & 0.151 \\
\hline Mechanical ventilation & 16 & 35.56 & 7 & 41.18 & 0.771 & 0.988 \\
\hline Infections & 21 & 46.67 & 9 & 52.94 & 0.778 & 0.951 \\
\hline Cardiac complications & 10 & 22.22 & 3 & 17.64 & 1.000 & 1.000 \\
\hline
\end{tabular}

$\mathrm{P}^{\prime}$ sds is the adjusted $\mathrm{p}$ value derived from the Holm step-down Sidak procedure for multiple comparisons.

\section{Disability assessments}

The GCS/15 was used to assess the depth and duration of a patient's coma and impaired consciousness (Figure 2). Results showed $\left({ }^{*}\right)$ a slow increase after admission and then a major increase between 48 hours post-CVA and ICU departure. After discharge from hospital there was a continuous but less marked improvement in the GCS.

The SIS-16 was used to provide an indication of a patient's state of dependency (Figure 3). Results showed $\left({ }^{*}\right)$ a strong improvement after hospital departure and in the three months following, although this improvement was less pronounced later. The Karnofsky score, which was used to give an indication of the patient's functional status, showed a similar evolution to the SIS-16 for both types of CVA.

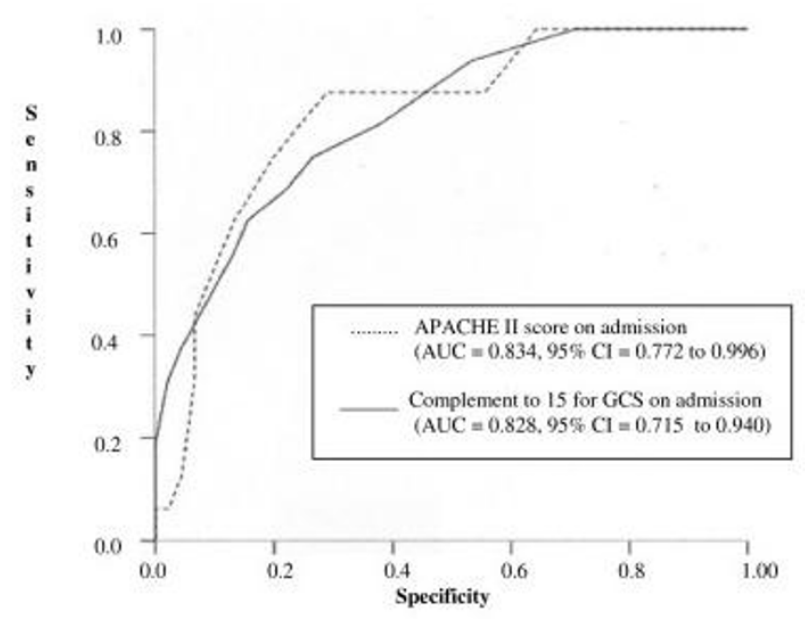

Figure I

Receiver operating characteristic curves (ROC) for APACHE II and GCS at admission.
Univariate analysis indicated that the patient's functional state (SIS-16) at discharge from hospital was influenced by age, GCS at hospital admission, type of CVA and duration of hospital stay, whereas other variables had little influence. Multivariate analysis incorporating linear regression was used to determine the definitive significant factors (Table 3).

One year after discharge, disability was essentially related to the SIS-16 at hospital discharge (Odds ratio (OR): $0.734(0.082)$ for ischemic and $0.374(0.024)$ for haemorrhagic stroke). Complementary factors in the ischemic group were: patient age (OR: $-0.534(0.190))$, mechanical ventilation (OR: $-10.921(5.238)$ ) and diabetes mellitus (OR: 16.043(4.547)). Complementary factors in the haemorrhagic group were: arterial hypertension (OR: -

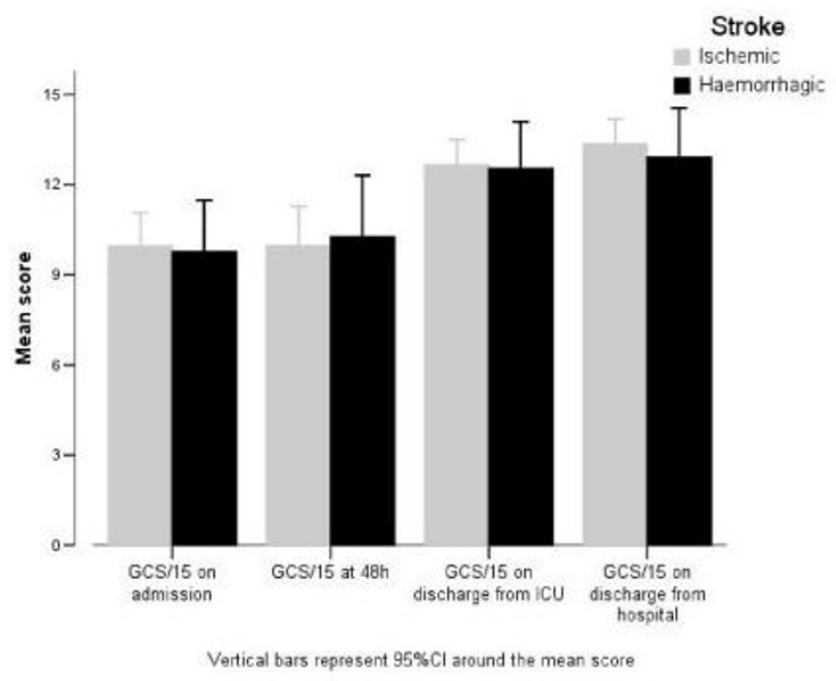

Figure 2

The Glasgow Coma Scale (GCS/I5) 


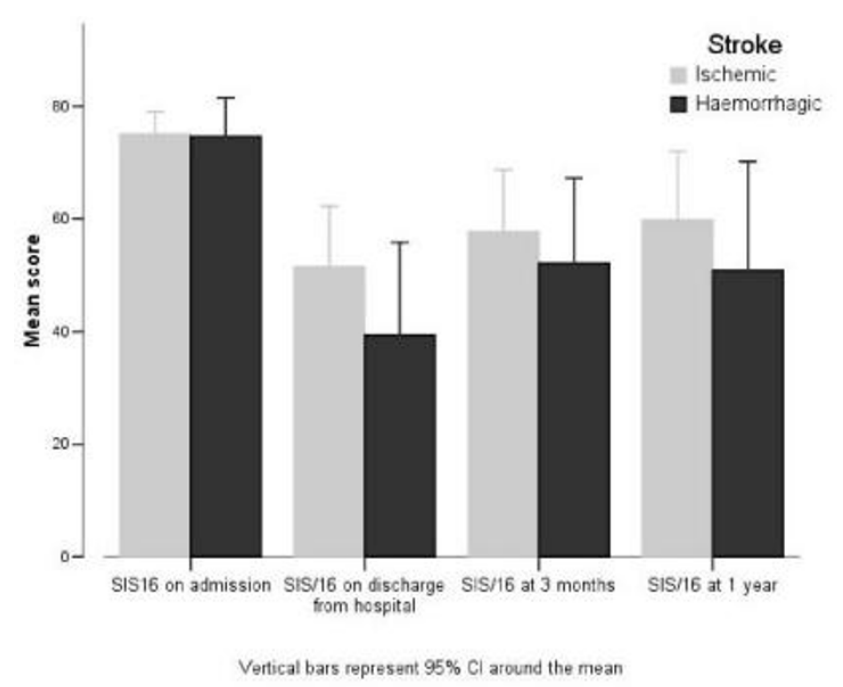

Figure 3

The Stroke Impact Scale I 6 (SIS- I6)

13.394(0.938)), mechanical ventilation (OR: 16.663(1.211)) and naso-gastric intubation (OR: 24.301(1.112)).

\section{Survival}

Among the 62 patients studied, 16 (25.8\%) died in the ICU and seven died in the year following hospital discharge. For the study period a Kaplan-Meier plot (Figure 4) showed a steady decline in patient numbers up to Day 100 with no further decline up to day 1000 . The significant factors determined by univariate analysis influencing survival were: patient age, history of smoking and cardiac insufficiency, delay between onset of symptoms and ICU admission, APACHE II and GCS at hospital admission, hospital length of stay, thrombolysis, and the requirement for sedation, anti-epileptic treatment, osmotic diuresis, naso-gastric intubation, mechanical ventilation and surgery.

To evaluate the impact of "duration of ventilation" on prognosis, we divided this variable into 3 class categories; 0 : no ventilation; 1 : ventilation $<72$ hours (short) and 2 : ventilation $>72$ hours (long). Univariate analysis of ventilation confirmed a bad prognosis with a risk ratio (RR) of 2.65 (95\% CI: 1.55 to 4.55; p < 10-3). Multivariate analysis using a Cox regression provided the three final independent variables shown below (Table 4). Using a multivariate analysis we also examined the effect of each day of mechanical ventilation on worsening the CVA patients' prognosis (Table 4).

\section{Discussion}

Although the development of new stroke units and treatment modalities have reduced the disabilities and mortalities caused by acute severe strokes, the real clinical benefits for the most severely affected group of patients remain highly speculative. This study analyzed the benefits and implications of the therapeutic resources used in treating critical stroke patients (ischemic and haemorrhagic) in respect to their survival and functional abilities. Disability was measured by the ordinal variable SIS-16, but was better predicted by linear regression. Prognosis was studied by taking into consideration both the time factor and Kaplan-Meier survival tables.

For the study period, severe stroke accounted for $7 \%$ of medical ICU admissions and $17.5 \%$ of all hospital stroke cases. The decision to admit a patient into the ICU was determined primarily by their level of consciousness, and for the urgency to use intensive therapeutic procedures, such as mechanical ventilation, sedation, anti-epileptics, diuretics, osmotic or steroid treatment and surgical interventions. Pre-stroke the patients were completely independent with a Karnofsky score higher than 90 for both types of CVA. After examining the GCS on admission, we found an average score of less than 10 for both ischemic and haemorrhagic CVAs, which had probably influenced their ICU admission [24]. Once admitted, patients underwent intensive therapeutic procedures such as; thrombolysis, unblocking respiratory airways, mechanical ventilation, haemodynamic monitoring and treatment for intracranial hypertension.

Taking ICU admission as our starting point, important differences were noted between ischemic and haemorrhagic CVA. All risk factors, excluding atrial fibrillation, were identical in the two types of CVA $[25,26]$. We found that ischemic CVA was better tolerated as haemorrhagic CVA patients frequently required sedation in order to administer anti-epileptic treatment, surgical interventions, or osmotic diuretics. On admission the level of consciousness measured by the GCS was lower in ischemic

Table 3: Factors that influence a patient's functional state and dependency at discharge from hospital; multivariate analysis

\begin{tabular}{|c|c|c|c|}
\hline & Linear coefficient & Standard Error & p-value \\
\hline (constant) & |4.99| & 12.425 & 0.273 \\
\hline GCS at admission & 6.833 & 1.077 & 0.001 \\
\hline Type of CVA Haemorrhagic vs Ischemic & -18.954 & 4.579 & 0.007 \\
\hline Duration of hospital stay (day) & -0.378 & 0.144 & 0.040 \\
\hline
\end{tabular}




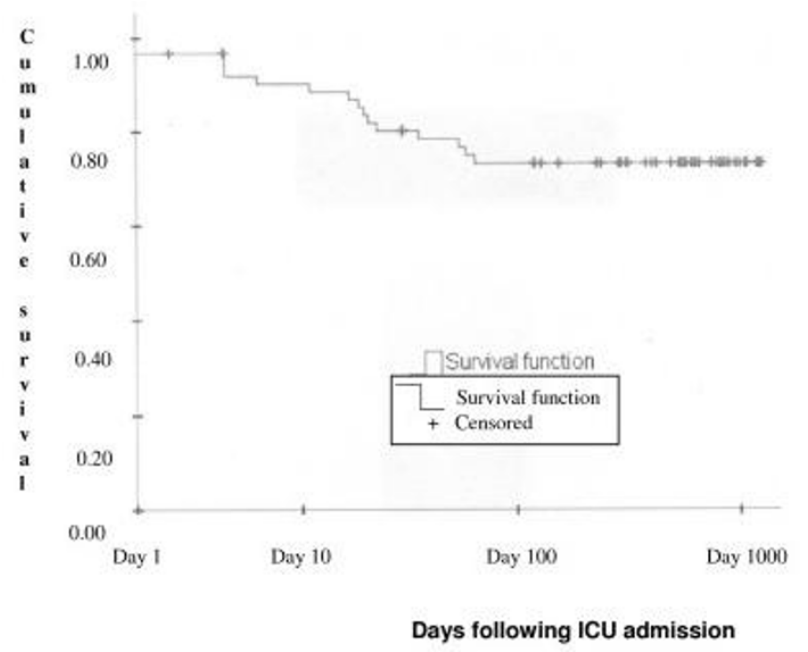

Figure 4

Kaplan Meier survival curve for severe stroke patients

CVA than in haemorrhagic CVA cases, and displayed a major increase between 48 hours post-CVA and ICU departure $[27,28]$. As previously seen in other studies [24,26,29-31] a strong improvement in functional ability (SIS-16/80) was noted after hospital departure and in the following 3 months, although this improvement was less pronounced at later times.

There are several factors that can predict the dependency status at hospital discharge, of these haemorrhagic CVA with a low level of consciousness on admission and a longer duration of hospital stay is associated with the worst functional ability. Moreover, on admission a severe haemorrhagic CVA with a GCS of 7 has more than 30 points less in the SIS-16 score at discharge than a severe ischemic CVA with a GCS of 9. Severe disability was identified in $40.5 \%$ of surviving patients on discharge, which decreased after one year to $24 \%$. This result confirms the Barthel Index results of Navarrete-Navarro et al. [24], who showed that $26 \%$ of severe stroke patients had a poor outcome and a severe functional disability after one year. Measuring neurological severity at hospital admission by
GCS is the main determinant of future functional capacity in CVA patients at discharge and after one year. Indeed, although the patients' functional ability had improved after one year, it would be best predicted by their functional ability at discharge. Surviving severe stroke patients increase the burden of the disease, due to their health care utilization, which necessitates acute care, rehabilitation and an increased discharge rate to nursing homes, which all contribute to the increased cost of the disease $[24,27,32,33]$.

Three independent factors contribute to the survival outcome of severe stroke patients. Of these, the decreased level of consciousness evaluated by GCS is the most important determinant of increased mortality. Mortality risk increases by $20 \%$ for each unit decrease in the GCS. Previous studies have confirmed the mortality prediction value of the GCS at admission, 30 days $[28,34]$ and oneyear later [24]. Moreover, a low GCS at admission coupled with an absence of pupillary light response corresponds to a poorer prognosis for survival [28].

Prognostic scoring systems such as APACHE can provide initial risk stratification for severely ill hospitalized patients. Studies have shown $[17,24]$ that APACHE can predict survival outcome independently. Scoring the severity of the neurological disease and the severity of the patients general health status on admission are both good survival rate predictors in severe stroke patients [24].

Endotracheal intubation and the necessity to apply mechanical ventilation in severe stroke patients for neurological reasons are accompanied by the worst prognosis. Many studies have shown that stroke patients requiring mechanical ventilation have a bad outcome and surviving patients remain deeply disabled [28,34-37]. Santoli et al. showed that an assessment of brain stem reflexes might help identify the subgroup of patients with a high probability of death despite mechanical ventilation [36]. Moreover, a short duration of mechanical ventilation $(<72$ hours) is still a bad predictor of survival with a risk ratio of 2.45 (95\% CI: 1.36 to $4.43 ; \mathrm{p}<0.003$ ). No difference between ischemic and haemorrhagic stroke patients was noted in terms of duration and requirement for mechani-

Table 4: Cox model for predicting survival

\begin{tabular}{|c|c|c|c|c|}
\hline \multicolumn{2}{|c|}{ Consideration } & \multirow{2}{*}{$\begin{array}{c}\text { Risk Ratio } \\
0.79\end{array}$} & \multirow{2}{*}{$\begin{array}{c}95 \% \mathrm{Cl} \\
0.66 \text { to } 0.95\end{array}$} & \multirow{2}{*}{$\frac{p \text {-value }}{0.012}$} \\
\hline Classes of mechanical ventilation & GCS at hospital administration & & & \\
\hline & APACHE II at hospital admission & 1.12 & 1.00 to 1.26 & 0.049 \\
\hline & Duration of mechanical ventilation (categorical) & 2.45 & 1.36 to 4.43 & 0.003 \\
\hline \multirow[t]{3}{*}{ Number of days on mechanical ventilation } & GCS at hospital admission & 0.80 & 0.66 to 097 & 0.024 \\
\hline & APACHE II at hospital admission & 1.12 & 1.00 to 1.24 & 0.050 \\
\hline & Duration of mechanical ventilation (days) & 1.07 & 1.01 to 1.15 & 0.046 \\
\hline
\end{tabular}


cal ventilation. Indeed, when we looked at the ICU interventions our results revealed (Table 2) that all these factors were uninfluenced by the cause of the patients' CVA.

\section{Conclusion}

When poorly selected patients are admitted into an ICU, inappropriate use of technology may not save lives, nor improve the quality of life, but rather transform dying into a prolonged, miserable and undignified process. We have shown that several factors and their assessments can help to identify the subgroup of patients that have an acutely reversible medical condition and are liable to have a potentially good functional recovery, from those that may suffer a prolonged and drawn out death regardless of any medical intervention. This raises important ethical questions: is it permissible to select certain patients for medical interventions and resources, and to condemn others to death without trying to intervene? Or, do these interventions constitute a therapeutic relentlessness that is an indispensable necessity?

The size of the cohort was limited as this study was conducted in only one centre over a 30 month period. Therefore, further studies involving a greater number of patients are urgently needed in order to shed some light on theses ethical and economical considerations.

\section{Abbreviations}

ANOVA: Analysis of variance; APACHE: Acute Physiology, Age, Chronic Health Evaluation; CVA: Cerebrovascular accident; ICU: Intensive care unit; GCS: Glasgow Coma Scale; OR: Odds ratio; RR: Risk ratio; SD: Standard deviation; SIS: Stroke impact scale.

\section{Competing interests}

We the authors declare that in the past five years have not received reimbursements, fees, funding, or salary from an organization that may in any way gain or lose financially from the publication of this manuscript, either now or in the future. There are no organizations financing this manuscript (including the article-processing charge). Do not hold any stocks or shares in an organization that may in any way gain or lose financially from the publication of this manuscript. Do not hold, or are currently applying for any patents relating to the content of this manuscript. We have you received reimbursements, fees, funding, or salary from an organization that holds or has applied for patents relating to the content of this manuscript. We do not have any other financial competing interests.

There are no non-financial competing interests (political, personal, religious, ideological, academic, intellectual, commercial or any other) to declare in relation to this manuscript.

\section{Authors' contributions}

MR: wrote the protocol, applied it, collected the data and wrote the original document. SK: wrote the original document. SH-C: wrote the original document. GS: performed the statistics. FS: collected the data. GD: collected data. TB: collected data. ZA-B: collected data. GK: collected data.

\section{Acknowledgements}

We would like to thank Jeffrey Jelly of Cedar Scientific Research, Lebanon who provided medical writing services.

\section{References}

I. Murray CJ, Lopez AD: Mortality by cause for eight regions of the world: Global Burden of Disease Study. Lancet 1997, 349(906 I): 1269-76.

2. Truelsen T, Mahonen M, Tolonen H, Asplund K, Bonita R, Vanuzzo D: Trends in Stroke and Coronary Heart Disease in the WHO MONICA Project. Stroke 2003, 34(6): 1346-1352.

3. How do stroke units improve patient outcomes? A collaborative systematic review of the randomized trials. Stroke Unit Trialists Collaboration. Stroke 1997, 28(I I):2139-44.

4. Indredavik B, Slordahl SA, Bakke F, Rokseth R, Haheim LL: Stroke unit treatment. Long-term effects. Stroke I997, 28(10): I 86I-6.

5. Denicourt C, Dowdy SF: Protein transduction technology offers novel therapeutic approach for brain ischemia. Trends Pharmacol Sci 2003, 24(5):216-8.

6. Onteniente B, Rasika S, Benchoua A, Guegan C: Molecular pathways in cerebral ischemia: cues to novel therapeutic strategies. Mol Neurobiol 2003, 27(I):33-72.

7. Sun $A$, Cheng J: Novel targets for therapeutic intervention against ischemic brain injury. Clin Neuropharmacol 1999, 22(3): $|64-7|$.

8. Dietrich WD, Busto R, Valdes I, Loor Y: Effects of normothermic versus mild hyperthermic forebrain ischemia in rats. Stroke 1990, 21 (9): 1318-25.

9. Evans A, Harraf F, Donaldson N, Kalra L: Randomized Controlled Study of Stroke Unit Care Versus Stroke Team Care in Different Stroke Subtypes. Stroke 2002, 33(2):449-455.

10. Ronning OM, Guldvog B, Stavem K: The benefit of an acute stroke unit in patients with intracranial haemorrhage: a controlled trial. J Neurol Neurosurg Psychiatry 200I, 70(5):63I-634.

II. Fagerberg B, Claeson L, Gosman-Hedstrom G, Blomstrand C: Effect of Acute Stroke Unit Care Integrated With Care Continuum Versus Conventional Treatment: A Randomized IYear Study of Elderly Patients: The Goteborg 70+ Stroke Study. Stroke 2000, 3 I (II):2578-2584.

12. Ronning OM, Guldvog B: Stroke Units Versus General Medical Wards, I: Twelve- and Eighteen-Month Survival: A Randomized, Controlled Trial. Stroke 1998, 29(I):58-62.

13. Ronning OM, Guldvog B: Stroke Unit Versus General Medical Wards, II: Neurological Deficits and Activities of Daily Living : A Quasi-Randomized Controlled Trial. Stroke 1998, 29(3):586-590.

14. Collaborative systematic review of the randomised trials of organised inpatient (stroke unit) care after stroke. Stroke Unit Trialists' Collaboration. Bmj 1997, 3 I 4(7088): I I I I-9.

15. Millikan $\mathrm{CH}$ : Stroke intensive care units: objectives and results. Stroke 1979, 10(3):235-7.

16. Marik PE: The cost of dying. Am J Crit Care 1995, 4(I):56-8.

17. Glance $L G$, Osler TM, Dick $A$ : Rating the quality of intensive care units: is it a function of the intensive care unit scoring system? Crit Care Med 2002, 30(9): 1976-82.

18. Teasdale G, Jennett $B$ : Assessment and prognosis of coma after head injury. Acta Neurochir (Wien) 1976, 34(I-4):45-55.

19. Teasdale G, Jennett $B$ : Assessment of coma and impaired consciousness. A practical scale. Lancet 1974, 2(7872):8I-4.

20. Lai SM, Perera S, Duncan PW, Bode R: Physical and social functioning after stroke: comparison of the Stroke Impact Scale and Short Form-36. Stroke 2003, 34(2):488-93.

21. Duncan PW, Lai SM, Bode RK, Perera S, DeRosa J: Stroke Impact Scale-16: A brief assessment of physical function. Neurology 2003, 60(2):291-6. 
22. de Haan R, Aaronson N, Limburg M, Hewer RL, van Crevel H: Measuring quality of life in stroke. Stroke 1993, 24(2):320-7.

23. Milstein JM, Cohen ME, Sinks LF: The influence and reliability of neurologic assessment and Karnofsky performance score on prognosis. Cancer 1985, 56(7 Suppl): 1834-6.

24. Navarrete-Navarro P, Rivera-Fernandez R, Lopez-Mutuberria MT, Galindo I, Murillo F, Dominguez JM, Munoz A, Jimenez-Moragas JM, Nacle B, Vazquez-Mata G: Outcome prediction in terms of functional disability and mortality at I year among ICU-admitted severe stroke patients: a prospective epidemiological study in the south of the European Union (Evascan Project, Andalusia, Spain). Intensive Care Med 2003, 29(8): 1237-44.

25. Hankey GJ: Preventable stroke and stroke prevention. J Thromb Haemost 2005, 3(8): 1638-45.

26. Karatas M, Dilek A, Erkan H, Yavuz N, Sozay S, Akman N: Functional outcome in stroke patients with atrial fibrillation. Arch Phys Med Rehabil 2000, 8I(8): I025-9. 27

27. Sheikh K, Brennan PJ, Meade TW, Smith DS, Goldenberg E: Predictors of mortality and disability in stroke. J Epidemiol Community Health 1983, 37(I):70-4.

28. Bushnell CD, Phillips-Bute BG, Laskowitz DT, Lynch JR, Chilukuri V, Borel CO: Survival and outcome after endotracheal intubation for acute stroke. Neurology 1999, 52(7):|374-8|.

29. Carod-Artal FJ, Gonzalez-Gutierrez JL, Herrero JA, Horan T, De Seijas EV: Functional recovery and instrumental activities of daily living: follow-up I-year after treatment in a stroke unit. Brain Inj 2002, 16(3):207-16.

30. Giaquinto S, Buzzelli S, Di Francesco L, Lottarini A, Montenero P, Tonin P, Nolfe G: On the prognosis of outcome after stroke. Acta Neurol Scand 1999, 100(3):202-8.

31. Lin JH, Tsai AY, Lo SK, Chang JJ, Huang MH: Predicting the grade of disabilty I year after stroke following rehabilitation. Kaohsiung J Med Sci 2005, 2 I (5):2 I 2-9.

32. Holloway RG, Benesch CG, Burgin WS, Zentner JB: Prognosis and decision making in severe stroke. Jama 2005, 294(6):725-33.

33. Jorgensen HS, Nakayama H, Raaschou HO, Olsen TS: Acute stroke: prognosis and a prediction of the effect of medical treatment on outcome and health care utilization. The Copenhagen Stroke Study. Neurology 1997, 49(5): | 335-42.

34. Mayer SA, Copeland D, Bernardini GL, Boden-Albala B, Lennihan L Kossoff S, Sacco RL: Cost and outcome of mechanical ventilation for life-threatening stroke. Stroke 2000, 3 I ( I 0):2346-53

35. Foerch C, Kessler KR, Steckel DA, Steinmetz, Sitzer M: Survival and quality of life outcome after mechanical ventilation in elderly stroke patients. J Neurol Neurosurg Psychiatry 2004, 75(7):988-93.

36. Santoli F, De Jonghe B, Hayon J, Tran B, Piperaud M, Merrer J, Outin $\mathrm{H}$ : Mechanical ventilation in patients with acute ischemic stroke: survival and outcome at one year. Intensive Care Med 200I, 27(7): I| |4|-6.

37. Leker RR, Ben-Hur T: Prognostic factors in artificially ventilated stroke patients. J Neurol Sci 2000, I76(2):83-7.

\section{Pre-publication history}

The pre-publication history for this paper can be accessed here:

http://www.biomedcentral.com/1471-2377/8/24/prepub
Publish with Biomed Central and every scientist can read your work free of charge

"BioMed Central will be the most significant development for disseminating the results of biomedical research in our lifetime. "

Sir Paul Nurse, Cancer Research UK

Your research papers will be:

- available free of charge to the entire biomedical community

- peer reviewed and published immediately upon acceptance

- cited in PubMed and archived on PubMed Central

- yours - you keep the copyright
Biomedcentral 